\title{
Chasing Clarity: Rumination as a Strategy for Making Sense of Emotions
}

\author{
Vera Vine $^{a}$, Amelia Aldao $^{b}$ \& Susan Nolen-Hoeksema ${ }^{a}$ \\ a Yale University \\ ${ }^{b}$ The Ohio State University
}

\begin{abstract}
Research is needed on the affective mechanisms that motivate people to ruminate. One possibility is that some people might ruminate in response to deficits in emotional clarity because not knowing how they feel might be intolerable to them. We tested the hypothesis that the relationship between low emotional clarity and rumination would be moderated by intolerance of ambiguity. Participants in a longitudinal online study $(N=195)$ provided selfreports of intolerance of ambiguity and rumination and reported state emotional clarity following an idiographic mood induction; three weeks later they reported on rumination again. As predicted, participants with low emotional clarity at Time 1 ruminated more three weeks later, but only if they were intolerant of ambiguity. Findings support the notion that rumination sometimes functions as a search for answers about emotions. We discuss implications for understanding the affective disturbances perpetuating vicious cycles of rumination and for rumination-focused clinical interventions.
\end{abstract}

(c) Copyright 2014 Textrum Ltd. All rights reserved.

Keywords: emotion, emotional clarity, emotion awareness, emotion understanding, rumination, emotion regulation, intolerance of ambiguity

Correspondence to: Vera Vine, M.S., M.Phil., Yale University, Department of Psychology, P.O. Box 208205, New Haven, CT 06520. Email: vera.vine@yale.edu

1. Yale University, Department of Psychology, P.O. Box 208205, New Haven, CT 06520.

2. The Ohio State University, Department of Psychology, 1835 Neil Avenue, Columbus, Ohio 43210

Received 03-Sep-2013; received in revised form 17-Apr-2014; accepted 01-Jun-2014 


\title{
Table of Contents
}

\author{
Introduction \\ Method \\ Recruitment \\ Participants \\ Retained vs. attritted subjects. \\ Mood Induction \\ Measures \\ Emotional clarity. \\ Rumination. \\ Intolerance of ambiguity. \\ Procedure \\ Results \\ Preliminary Analyses \\ Manipulation check. \\ Descriptive analyses and bivariate correlations. \\ Main Analyses \\ Discussion \\ Limitations and Strengths \\ Clinical Implications and Future Directions \\ Conclusion \\ Acknowledgements \\ References
}

\section{Introduction}

"People, not constructs." This phrase became familiar to all of Susan's students. She would write it in the margins of our drafts and repeat it when we discussed each other's manuscripts in lab meetings. Now, in Susan's absence, we often return to this phrase. On the surface, Susan meant that we should improve our writing by using dynamic, people-centered language and clinical examples, instead of psychological jargon; indeed, her own writing was always lucid and unpretentious. But this phrase is about more than writing. It reminds us that what ultimately matters in this profession is not -isms, not models with boxes and arrows, but human experience-often human suffering. We believe that what drove Susan to conduct her research on rumination, and part of what made her research so influential, was her abiding curiosity about what it is like to be human. 'People, not constructs' also encapsulates how it felt to interact with Susan. It did not matter that she was a legendary scholar or the Chair of the department; she never put on airs. She had a particular way of regarding everyone she spoke to: steadily, seriously, and with a kind of quiet intensity that communicated her eagerness to listen. We pay tribute to Susan and her fundamental interest in others by attempting to exemplify 'people, not constructs' in our presentation of the current study.

In her seminal work on rumination, Susan Nolen-Hoeksema (1991) conceptualized this process as a maladaptive style of thinking in which people perseverate on the causes, consequences, and meanings of their negative affect. Since then, extensive research has shown that rumination exacerbates sad mood, impairs problem solving, reduces instrumental behavior, and drives away social support (see Nolen-Hoeksema, Wisco, \& Lyubomirsky, 2008). Moreover, rumination has been associated with the development and maintenance of a wide range of mental disorders, such as depression, anxiety, eating disorders, and substance abuse problems (see Aldao, NolenHoeksema, \& Schweizer, 2010). One of the problematic features of rumination is that it is self-perpetuating: it is relatively easy to fall into a ruminative cycle, and it is also quite difficult to stop once it has begun (e.g., Gotlib \& Joormann, 2010; Lyubomirsky \& Nolen-Hoeksema, 1993; Nolen-Hoeksema et al., 2008; Smith \& Alloy, 2009; Watkins, 2008). Given these difficulties interrupting rumination, it is critical that we develop a more nuanced understanding of the mechanisms that initiate the ruminative cycle in the first place. Identifying such "upstream" mechanisms will show us how to bypass rumination cycles before they even start and consequently, could inform 
prevention programs and psychosocial interventions (Watkins et al., 2011). In this investigation, we shed light on affective mechanisms that might drive people to ruminate in the first place. Specifically, we examined the possibility that some people ruminate as a response to the discomfort of not understanding which emotions they feel.

Several lines of research suggest that one important reason why people ruminate is to search for answers to personally salient questions. Ruminators tend to believe that ruminating will help them gain insight into themselves and their problems (Papageorgiou \& Wells, 2001, 2002; Watkins \& Baracaia, 2001; see also co-rumination, Rose, Carlson, \& Waller, 2007). One study has also found that participants rated themselves as more insightful individuals after being randomly assigned to ruminate versus distract themselves with neutral thoughts (Lyubomirsky \& Nolen-Hoeksema, 1993), which suggests that the experience of ruminating might feel like a process of finding insight. Rumination may be a strategy for making sense of uncertainty about the future (de JongMeyer, Beck, \& Riede, 2009; Liao \& Wei, 2011; Yook, Kim, Suh, \& Lee, 2010), and for understanding and resolving discrepancies between current and ideal states when pursuing goals (Martin \& Tesser, 1996; Moberly \& Watkins, 2010; Pyszczynski \& Greenberg, 1987; Watkins, 2008).

We propose to examine the use of rumination in relation to the task of making sense of a specific uncertain state that is particularly relevant for the work on emotion regulation: low emotional clarity. Emotional clarity has been conceptualized as the subjective experience of having difficulty identifying which emotions one feels (e.g., Gohm \& Clore, 2002; Salovey, Mayer, Goldman, Turvey, \& Palfai, 1995). Deficits in emotional clarity have been associated with symptoms of mental disorders (e.g., Boden, Gross, Babson, \& Bonn-Miller, 2013; Flynn \& Rudolph, 2010; Mennin, Holaway, Fresco, Moore, \& Heimberg, 2007; Spokas, Luterek, \& Heimberg, 2009), leading emotional clarity to be conceptualized as a transdiagnostic process that accounts for dysfunction across psychopathology (Vine \& Aldao, 2014). Importantly, the ability to be clear about one's emotions is increasingly being considered a precursor to the regulation of emotions (e.g., Barrett, Gross, Christensen, \& Benvenuto, 2001; Boden, Bonn-Miller, Kashdan, Alvarez, \& Gross, 2012; Flynn \& Rudolph, 2010; Kashdan, Ferssizidis, Collins, \& Muraven, 2010), which renders it an ideal candidate for the examination of upstream processes preceding rumination.

A few studies have linked low emotional clarity with constructs that are functionally similar to rumination. For instance, a structural equation model in a sample of children associated low self-reported emotional clarity with a latent variable constructed in part from a measure of involuntary engagement coping that included rumination items (Flynn \& Rudolph, 2010). In another study, the association between emotional clarity and depression was mediated by self-reported difficulty disengaging attention from goal-irrelevant stimuli (Vine \& Aldao, 2014), an emotion regulatory deficit reminiscent the cognitive impairment associated with rumination (Gotlib \& Joormann, 2010). Finally, participants reporting deficits in emotional clarity at the trait level responded with more negative, uncontrollable, and insistent thoughts following a negative mood induction, suggestive of a higher ruminative response (Salovey et al., 1995). To our knowledge, only one existing study has gone a step further to characterize the nature of the relationship between emotional clarity and rumination. As part of a larger meta-mood model of depression, Salguero, Extremera, and Fernández-Berrocal (2013) demonstrated an indirect statistical path from low emotional clarity to rumination through self-reported difficulties repairing negative mood, which they interpreted as evidence that people with low emotional clarity might turn to rumination in essence as a default, because of their inability to repair mood in any other way. Yet, it remains possible that people with low emotional clarity turn to rumination not only for lack of another emotion regulation strategy, but because they seek a specific remedy to the problem of not fully understanding how they feel.

If indeed rumination functions as a search for emotional clarity, then this process would most likely play out only among those individuals troubled by not having emotional clarity. Simply put, people search for things when they are bothered by not having them; only the individual bothered by mismatching socks goes in search of a lost one. People vary in their ability to feel comfortable with stimuli they do not understand or that are subject to multiple interpretations, a trait known as intolerance of ambiguity (Budner, 1962; McLain, 1993). Unlike the intolerance of uncertainty construct, which concerns distress about unknown future events, intolerance of ambiguity refers uncertainty in present-moment situations (Grenier, Barrette, \& Ladouceur, 2005), which could apply to states of low emotional clarity. Fundamentally, our account of rumination as a search for emotional clarity presupposes that the relationship between low emotional clarity and rumination is moderated by intolerance of ambiguity, such that individuals bothered by ambiguity would be more motivated to ruminate in response to not knowing how they feel. 
In the current investigation, we tested this moderation hypothesis using a longitudinal online sample. To improve upon the validity made possible by trait-based measures of emotional phenomena (Robinson \& Clore, 2002), we assessed emotional clarity in a state-based manner in the context of negative moods related to personally relevant, upsetting events. In order to shed light on the temporal aspect of the relationship between emotional clarity and rumination, we assessed rumination at two time points. Participants provided self-reports of intolerance of ambiguity and rumination and reported state emotional clarity following an idiographic mood induction. Then, three weeks later, they reported on rumination again. We predicted that participants with low emotional clarity at Time 1 would ruminate significantly more three weeks later if they were intolerant of ambiguity.

\section{Method}

\section{Recruitment}

The present investigation utilizes data from the first and third assessments of a larger study conducted across three time points, since this longer interval would help to more adequately evaluate changes in rumination over time. We recruited participants using Amazon's Mechanical Turk (mTurk.com), an internet-based crowdsourcing platform. On mTurk, individuals ("workers") select tasks they wish to complete for pay, such as psychological surveys, from among thousands of tasks posted by other users ("requesters"). MTurk workers have been shown to be highly motivated to complete tasks regardless of levels of pay (Buhrmester, Kwang, \& Gosling, 2011), and tend to provide reliable behavioral data comparable to that obtained in laboratory participants (Crump, McDonnell, \& Gureckis, 2013; Goodman, Cryder, \& Cheema, 2012; Paolacci, Chandler, \& Ipeirotis, 2010). Importantly, recent investigations suggests that mTurk is suited to clinical research, as typical mTurk samples report levels of depression, anxiety, trauma exposure, and substance use difficulties that meet or exceed national rates (e.g., Aldao \& Nolen-Hoeksema, 2012; Shapiro, Chandler, \& Mueller, 2013).

We limited the study to participants aged 18 and older, residing in the United States, and holding an approval rating of $95 \%$ or higher on prior mTurk tasks. Participants responding to the listing for a questionnaire-based study entitled, "The Personality, Emotion, and Imagination Study," were directed to an external website (Qualtrics.com) to complete the initial assessment, which was designed to take approximately 45-50 minutes. We followed recommendations by other researchers and used stringent criteria to determine eligibility for compensation (e.g., Oppenheimer, Meyvis, \& Davidenko, 2009; Pennycook, Cheyne, Seli, Koehler, \& Fugelsang, 2011; Prince, Litovsky, \& Friedman-Wheeler, 2012). We paid participants $\$ 3$ if they reported a unique mTurk worker ID and showed a unique computer IP Address, spent at least half the expected time completing the study, and passed a sufficient number of "attention check" questions. Attention check items were embedded within questionnaires and instructed participants to leave that item blank to show they were reading carefully.

Upon completing the first assessment, participants were given the opportunity to provide their email address in order to be re-contacted for two follow-up assessments, designed to take 35-40 and 25-30 minutes, respectively, and scheduled approximately 10-12 days apart. Participants received $\$ 2$ for each follow-up assessment and an additional $\$ 2$ bonus if they completed all 3 assessments. Participants opting to complete follow-ups received an email 8 days later reminding them that an assessment was coming soon. After 1-3 more days, they were notified that the assessment was currently posted and available for 5 days. Participants received targeted reminder emails as needed when they had 3,2, and 1 days remaining to complete the follow-up. To give priority to complete sets of data, we did not invite for a third assessment those participants who missed the second assessment. Participants were fully debriefed upon declining follow-up assessments or completing the third assessment.

\section{Participants}

Of the 387 participants who completed the Time 1 assessment, 24 were removed from the dataset because they missed 3 or more of the 13 "attention check" items embedded within the measures. We removed data from 5 additional participants who completed the survey in less than 25 minutes, leaving a total of 359 participants at Time 1. Of the 281 participants who completed the Time 2 assessment, 4 were removed for missing 3 or more of the 10 attention check items, and 22 were removed for taking less than 20 minutes. Further, 11 were removed for 
completing the Time 2 assessment twice (we retained the first administration, unless it was clear that participants had barely begun the first time and returned to complete it in full). This left a total sample of 244 for the Time 2 assessment. Of the 214 participants who completed the Time 3 assessment, 2 were removed for missing 2 or more of the 8 attention check items, 6 for taking less than 15 minutes, and 7 for completing the assessment a second time, leaving a total of 199 participants at Time 3. Retention rates $(72.61 \%$ at Time $2 ; 76.10 \%$ at Time 3) were within the $60-80 \%$ range over comparable timeframes in previous mTurk studies (Buhrmester et al., 2011; Shapiro et al., 2013).

For the present study, we used data from the 195 participants $(66.7 \%$ female) who completed all measures of interest. The mean age of the sample was $34.8(S D=11.4$, range 18-66). In terms of the ethnic breakdown, $80.5 \%$ identified as Caucasian, $8.7 \%$ as African American, 6.2\% as Hispanic or Latino, 7.2\% as Asian or Asian-American, $2.1 \%$ as Native American, and $1.5 \%$ as "other." Fifty two percent of participants reported they had not completed college. The mean interval between the assessments used in the present investigation was 22.58 days $(S D=$ 2.76).

\section{Retained vs. attritted subjects.}

We examined demographic data for differences between the final sample of 195 and the participants who did not complete all three assessments. Compared to participants who were not retained, participants in the final sample were marginally more likely to be female, $66.7 \%$ vs. $57.3 \%, \chi^{2}=3.32, p<.07$, and to identify as Caucasian, $80.5 \%$ vs. $73.2 \%, \chi^{2}=2.73, p<.10$. The final sample was significantly older than participants who were not retained (Ms 34.8 vs. 29.1 years), $F(1,357)=26.36, p<.001$, so we initially included age as a covariate in main analyses. However, this did not affect significant findings, so we removed age for the sake of parsimony. ${ }^{1}$

\section{Mood Induction}

Participants underwent a brief, idiographic mood induction in which they were asked first to select and then to immerse themselves in an upsetting memory. The memory selection phase provided the following instructions: "Think of an event in your life when someone close to you made you extremely upset. If you can think of more than one upsetting conflict, event, or experience, pick the event that still makes you the most upset and continues to feel the most unresolved." These instructions deliberately did not indicate a specific target emotion, so as not to provide participants the 'answer' about how they were feeling and to leave more room for variabilty in emotional clarity. To understand the content of participants' memories, we immediately asked participants to type a 180character description of the experience they had selected and report when it had happened and how resolved it currently felt. The first question was phrased, "How long ago did it happen? If it is an ongoing or repeating event, answer based on the last time it happened." Participants replied using a 5-point ordinal scale ( $1=$ two years ago or more; 2 = one year ago; $3=$ in the last year; $4=$ in the last month; $5=$ in the last week). The second question read, "How resolved does the conflict feel" and directed participants to respond on a 5-point Likert scale (1 = not at all; 2 = a little; 3 = somewhat 4 = moderately; 5 = mostly or completely).

We adapted the immersion phase of the mood induction from a previously validated procedure (Kross, Ayduk, \& Mischel, 2005). In order to increase the interactive nature of the induction, and to ensure that participants did not become distracted or leave their computers during this portion of the procedure, we asked participants to write about their memory as they re-experienced it. Instructions for this phase read:

For the next few minutes, try to re-experience the event as vividly as you can. Picture the event happening to you all over again. Picture in your "mind's eye" the surroundings as clearly as possible. See the people or objects; hear the sounds; experience the events happening to you. Think the thoughts that this event makes you think. Feel the same feelings that this event makes you feel. Let yourself react as if you were actually in the middle of it right now.

\footnotetext{
${ }^{1}$ The pattern of significant findings was also unaffected by covarying gender and ethnicity.
} 
While you re-experience the event, write about what is happening in the situation, how the other person or people involved behaved toward you, and what you are thinking. The screen will advance on its own when the time is up. Begin writing now.

Participants were given 130 seconds to read these instructions and write about their memory. We selected this relatively short time frame in order to prevent participants from experiencing therapeutic effects of self-disclosing (Pennebaker, 1997) or growing bored. Immediately following the immersion participants reported how vividly they had re-imagined or remembered the experience and how upset they felt in that exact moment on a 5-point Likert scale ( 1 = not at all; 2 = a little; 3 = somewhat; 4 = moderately; 5 = very much).

\section{Measures}

\section{Emotional clarity.}

Participants reported how clearly they understood their emotions about the upsetting memory using the state version of the Clarity subscale of the Difficulties in Emotion Regulation Scale (DERS; Gratz \& Roemer, 2004; see McLaughlin, Mennin, \& Farach, 2007). Participants rate their agreement with 5 statements on a 5-point Likert scale (e.g., 'I am confused about how I am feeling'). We keyed items so that higher numbers represent higher emotional clarity. Internal consistency in our sample was good, $\alpha=.90$.

\section{Rumination.}

We assessed rumination using the 5-item Brooding subscale of the Ruminative Response Styles scale (Treynor, Gonzalez, \& Nolen-Hoeksema, 2003), which assess the extent to which people engage in repetitive thought processes when feeling sad, blue, or depressed. We utilized the Brooding subscale, which has been shown to be independent of symptoms of depression (e.g., Treynor et al., 2003). Reliability in our sample was acceptable, $\alpha=$ .76 at Time 1 and $\alpha=.86$ at Time 3 .

\section{Intolerance of ambiguity.}

We assessed intolerance of ambiguity using the Multiple Stimulus Types Ambiguity Tolerance test (MSTAT-I; McLain, 1993), a 22-item measure of positive and negative affective responses to situations that are unfamiliar, complex, uncertain, or subject to multiple interpretations (e.g., 'I dislike ambiguous situations,' 'I'm drawn to situations which can be interpreted in more than one way'). Participants rate their agreement with each item on a 7point Likert scale. We keyed items so that higher scores reflect intolerance of ambiguity. Reliability in our sample was good, $\alpha=.88$.

\section{Procedure}

At Time 1, participants completed a trait battery containing the measures of rumination and intolerance of ambiguity. Following the trait measures, they completed the mood induction procedure and reported their emotional clarity. At Time 3, participants completed a similar battery of trait questionnaires that contained the same measure of rumination.

\section{Results}

\section{Preliminary Analyses}

\section{Manipulation check.}

All participants in the final sample had completed the 180-character descriptions of their memories. Informal review of these responses confirmed that they had selected upsetting interpersonal memories as instructed. Common themes included loss (e.g., "Our son died unexpectedly"), betrayal (e.g., "My ex-husband took our son away from me and lied to gain temporary custody"), interpersonal conflict (e.g., "I am an atheist and when I told my father he 
became very upset"), financial conflict (e.g., "Having my mother default on a loan agreement"), and social rejection (e.g., "My colleagues gossip about me behind my back"). One hundred and fourteen participants (58.5\%) selected memories of experiences they said had occurred 2 years ago or more. Participants reported that these experiences still felt unresolved, $M=2.55, S D=1.43$, mode (33.3\% of participants) $=1$ (Not at all resolved). On average, participants reported re-imagining the experience moderately to very vividly, $M=4.24, S D=.85$, mode $(46.7 \%$ of participants) $=5$ (very vividly). They also reported feeling upset, $M=3.20, S D=1.32$, mode $(26.2 \%$ of participants) $=4$ (moderately upset).

\section{Descriptive analyses and bivariate correlations.}

Means, standard deviations, and zero-order correlations of study variables appear in Table 1. Variables were largely uncorrelated, but emotional clarity was significantly associated with rumination at both time points ( $p s<$ $.001)$.

Table 1: Sample Characteristics and Bivariate Correlations for Variables at Relevant Time Points

\begin{tabular}{|c|c|c|c|c|c|c|c|c|}
\hline & $M(S D)$ or Frequency & 1. & 2. & 3. & 4. & 5. & 6. & 7. \\
\hline 1. Age & $34.82(11.44)$ & - & & & & & & \\
\hline 2. Caucasian & 157 (80.5\%) & .10 & - & & & & & \\
\hline 3. Female & 130 (66.7\%) & .13 & .06 & - & & & & \\
\hline 4. Emotional Clarity & $4.29(.85)$ & .07 & .04 & .10 & - & & & \\
\hline 5. Intolerance of Ambiguity & $85.10(18.96)$ & .05 & .01 & -.01 & -.10 & - & & \\
\hline 6. Time 1 Rumination & $11.28(3.34)$ & $-.14^{\dagger}$ & -.06 & .12 & $-.30^{\star \star *}$ & .11 & - & \\
\hline 7. Time 3 Rumination & $10.61(3.88)$ & $-.13^{\dagger}$ & -.09 & .10 & $-.31^{\star \star \star}$ & .10 & $.79^{\star \star \star}$ & - \\
\hline
\end{tabular}

Note. ${ }^{\dagger} p<.10 .{ }^{* \star *} p<.001$.

\section{Main Analyses}

To examine the hypothesis that intolerance of ambiguity would moderate the relationship between emotional clarity and rumination over time, we constructed a hierarchical linear regression model predicting rumination scores at Time 3. We used untransformed scores on trait measures because sample distributions were sufficiently normal, as indicated by skewness statistics below 2 (Tabachnik \& Fidell, 2007). To improve the interpretability of results, we centered the predictor variables. In the first step, we entered Time 1 rumination as a covariate, which explained the majority of the variance in Time 3 rumination (adjusted $\left.R^{2}=62.0 \%\right), F(1,193)=317.39, p<.001$. In the second step, we entered emotional clarity and intolerance of ambiguity scores, which did not account for any added variance in Time 3 rumination scores, $R^{2} \Delta=0.01, F(2,191)=1.80, p>$.16. However, adding the emotional clarityby-intolerance of ambiguity interaction term in the final step of the model accounted for a significant increase in variance in Time 3 rumination scores, $R^{2} \Delta=0.01, F(1,190)=4.90, p<.03$. As shown in Table 2, the main effect of emotional clarity, which was marginally significant, $b=-.36$, $S E=.21, t=-1.73, p<.10$, was qualified by an interaction with intolerance of ambiguity, $b=-.02, S E=.01, t=-2.21, p<.03$.

We probed the interaction using the PROCESS macro by Hayes (2013) and found a pattern consistent with our hypothesis. The conditional effect of emotional clarity on Time 3 rumination was not significant at the $10^{\text {th }}, 25^{\text {th }}$, and $50^{\text {th }}$ percentile values of intolerance of ambiguity, but was significant at the $75^{\text {th }}$ and $90^{\text {th }}$ percentile values. In other words, among participants very low, low, and moderate in intolerance of ambiguity, emotional clarity did not predict change in rumination over time. In contrast, among participants high and very high in intolerance of ambiguity, low emotional clarity following the mood induction predicted increased rumination at Time 3 (see Table 2 and Figure 1). Following Hayes (2013) we further probed the interaction using the Johnson-Neyman technique to estimate the specific value of intolerance of ambiguity at which the conditional effect of emotional clarity becomes significant. This value was 87.38 , which falls slightly above the sample mean of 85.10 and median of 85.00 and well within the observed range of 41-139. In other words, for participants in approximately the top half of the distribution of intolerance of ambiguity scores, experiencing low emotional clarity in the context of upsetting memories was a liability for later rumination. 
Table 2: Predictors of Time 3 Rumination

\begin{tabular}{|c|c|c|c|c|c|c|}
\hline Predictor & $R^{2} \Delta$ & $\boldsymbol{F}$ & $\boldsymbol{b}$ & $S E$ & $t$ & $p$ \\
\hline \multicolumn{7}{|l|}{ Hierarchical regression model } \\
\hline Step 1 & .622 & 317.39 & & & & .000 \\
\hline T1 Rumination & & & .92 & .05 & 17.82 & .000 \\
\hline Step 2 & .007 & 1.80 & & & & .167 \\
\hline T1 Rumination & & & .88 & .05 & 16.44 & .000 \\
\hline Emotional Clarity & & & -.40 & .21 & -1.87 & .063 \\
\hline Intolerance of Ambiguity & & & .00 & .01 & .20 & .841 \\
\hline Step 3 & .009 & 4.90 & & & & .028 \\
\hline T1 Rumination & & & .88 & .05 & 16.55 & .000 \\
\hline Emotional Clarity & & & -.36 & .21 & -1.73 & .092 \\
\hline Intolerance of Ambiguity & & & .00 & .01 & .26 & .799 \\
\hline Emotional Clarity $\mathrm{x}$ & & & -.02 & .01 & -2.21 & .028 \\
\hline \multicolumn{7}{|l|}{ Intolerance of Ambiguity } \\
\hline \multicolumn{7}{|c|}{ Conditional effect of emotional clarity at values of intolerance of ambiguity } \\
\hline $10^{\text {th }}$ Percentile (59.00) & & & .20 & .34 & .59 & .556 \\
\hline $25^{\text {th }}$ Percentile $(74.00)$ & & & -.12 & .24 & -.51 & .611 \\
\hline $50^{\text {th }}$ Percentile (85.00) & & & -.36 & .21 & -1.72 & .086 \\
\hline $75^{\text {th }}$ Percentile (96.00) & & & -.60 & .23 & -2.62 & .009 \\
\hline $90^{\text {th }}$ Percentile (109.00) & & & -.88 & .30 & -2.91 & .004 \\
\hline
\end{tabular}

Note. Parenthetical values in lower portion of table represent corresponding raw values on the Multiple Stimulus Types Ambiguity Tolerance test (MSTAT-I).

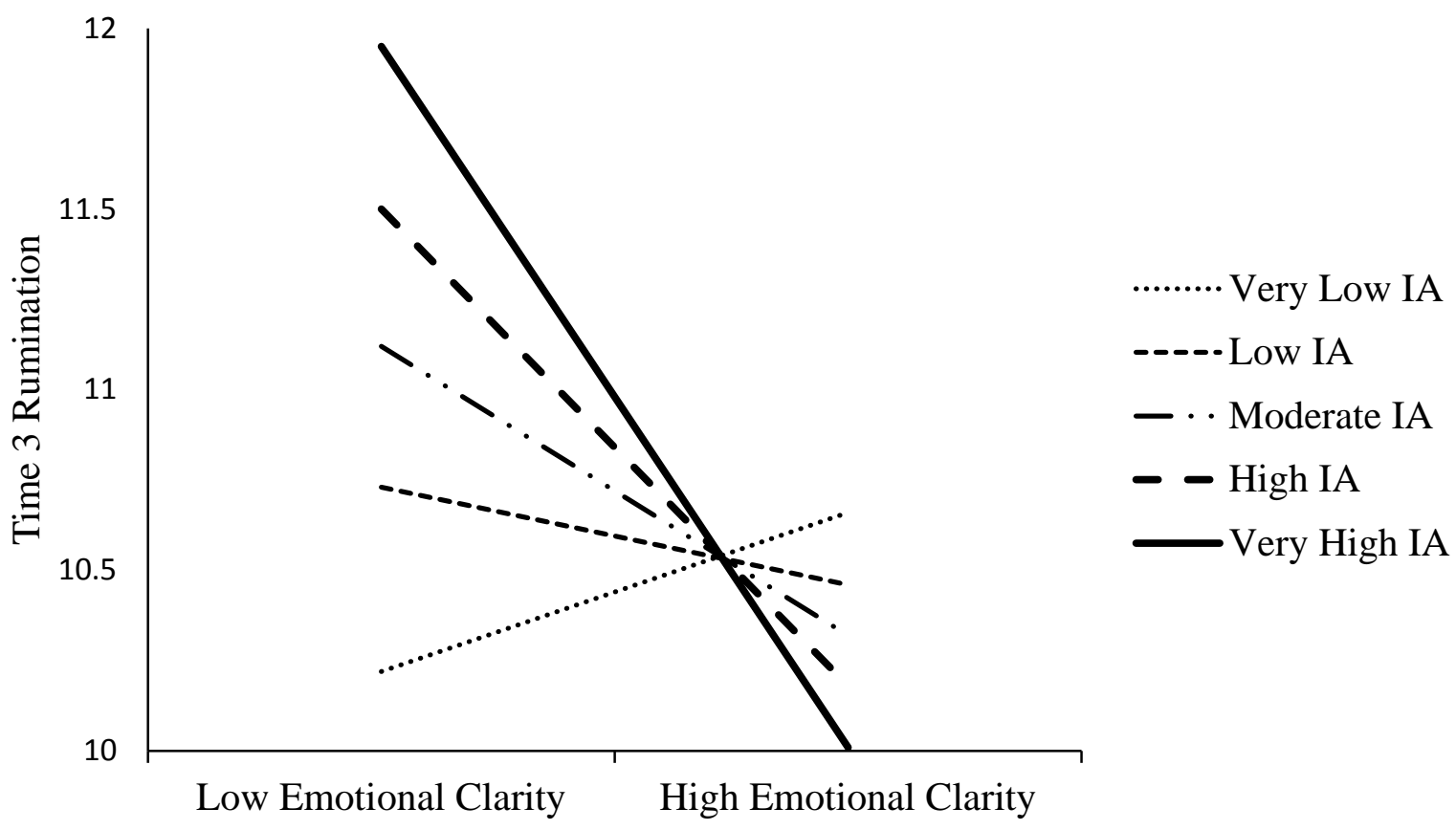

Figure 1: Moderation of the relationship between emotional clarity and Time 3 rumination by intolerance of ambiguity, controlling for Time 1 rumination. IA = intolerance of ambiguity. Relationships are estimated at a raw value of 2.8 for low emotional clarity and 5.0 for high emotional clarity and at $10^{\text {th }}, 25^{\text {th }}, 50^{\text {th }}, 75^{\text {th }}$, and $90^{\text {th }}$ percentile values of intolerance of ambiguity. 


\section{Discussion}

Rumination is difficult to interrupt once it has begun (e.g., Lyubomirsky \& Nolen-Hoeksema, 1993), so it is essential to understand the mechanisms that might lure people into ruminating in the first place. The present study extends the literature on the reasons why people ruminate by providing preliminary support for the hypothesis that some people ruminate in response to low emotional clarity. As we predicted, the relationship between emotional clarity and changes in rumination three weeks later was moderated by initial intolerance of ambiguity. Participants with low emotional clarity ruminated more three weeks later, but only if they were the kind of people who experienced not knowing as aversive. These findings have implications for enhancing our understanding of basic mechanisms underlying rumination, emotion dysregulation, and psychopathology, and for optimizing clinical interventions.

Our findings are broadly consistent with previous studies suggesting that people might ruminate in order to search for answers to personally salient questions (Martin \& Tesser, 1996; Papageorgiou \& Wells, 2001, 2002; Watkins \& Baracaia, 2001). They also extend this literature by suggesting a novel, emotion-specific variant of this idea: that rumination might function as a search for answers specifically about which emotions people are feeling. The link between rumination and low emotional clarity has been observed before (Flynn \& Rudolph, 2010; Salguero et al., 2013), but to our knowledge we are the first to 'zoom in' with the goal of explaining why low emotional clarity might predict rumination in particular. In the meta-mood model of depression by Salguero et al. (2013), low emotional clarity predicted rumination by way of low self-reported ability to repair emotions, suggesting that depressed individuals might default to ruminating because they believe they are unable to regulate their emotions effectively. Although we cannot assume causality based on our methods, our study raises an alternative possibility that for some individuals, rumination is rather a motivated search for answers fueled by dislike of ambiguity.

A relatively distinct 'why ruminate' literature suggests that people might ruminate to suppress or avoid unwanted internal experiences (i.e., experiential suppression; Giorgio et al., 2010; Liverant, Kamholz, Sloan, \& Brown, 2011). Our findings can be interpreted in light of this literature as well because they suggest that low emotional clarity might be one such type of aversive internal experience that individuals wish to avoid. Although we did not measure distress per se, intolerance of ambiguity by definition involves a distress or discomfort in the face of unclear stimuli (McLain, 1993). Thus, the significant moderation by intolerance of ambiguity implies that low emotional clarity might predict rumination because not knowing how one feels might be distressing for some people. In order to provide a stronger test of our theory, and to explore links to experiential suppression, it will be fruitful to develop ways of assessing the distress associated with unclear emotional states more directly. It will also be important to use experimental paradigms to assess the functional relationship between emotional clarity and rumination in a number of contexts (Aldao, 2013).

It is interesting to consider whether the relationship between emotional clarity and intolerance of ambiguity we found would generalize to forms of repetitive thought other than rumination. Reflective pondering may also arise in the presence of negative mood, but might ultimately facilitate effective problem solving and reduce depression symptoms over time (Martin \& Tesser, 1996; Treynor et al., 2003). Given its more adaptive nature, it is possible that reflective pondering occurs under more favorable conditions, such as when tolerance for ambiguity is higher or emotions are clearer. Alternatively, the presence of another moderating variable might be required to explain why some individuals ponder reflectively instead of ruminating. Worry also resembles rumination, but whereas ruminators typically seek answers about their negative affect and past or current problems, worriers seek answers about uncertain future events (Freeston, Rhéaume, Letarte, Dugas, \& Ladouceur, 1994; Nolen-Hoeksema et al., 2008). Worry has been associated with low emotional clarity (Salters-Pedneault, Roemer, Tull, Rucker, \& Mennin, 2006) and characterized as a means of suppressing the distress associated with intense, poorly understood emotions (Mennin \& Fresco, 2009). This portrayal of worry would suggest that worry might also serve as a response to low emotional clarity. However, the phenomenological differences in worry content suggest it might not necessarily function as a search for answers about emotions per se.

The present research has implications for both affective and clinical science. It is the premise of many psychosocial interventions that problems understanding emotions may lead to difficulties regulating them adaptively (e.g., Linehan, 1993; Mennin \& Fresco, 2009). Our study contributes a novel account of how this process may work in some cases. The relationship between understanding and regulating emotions is typically explained in terms of an 
affect as information framework: emotions provide information about the situation (Schwarz \& Clore, 1983), so confusion about emotions interferes with decision-making about how to regulate them (Barrett et al., 2001; Baumeister, Vohs, DeWall, \& Zhang, 2007). The present account of rumination goes beyond the mere lack of information about what one feels, and underscores the experience of that lack of information, which may provoke rumination because it feels intolerable to some people. This mechanism, if it is supported by future research, could be relevant to a number of mental disorders. We recently identified low emotional clarity as a transdiagnostic risk factor for at least five forms of psychopathology that likely operates through mechanisms involving problems in emotion regulation (Vine \& Aldao, 2014). Rumination also occurs transdiagnostically (McLaughlin \& NolenHoeksema, 2011). Thus, our model of rumination as a response to low emotional clarity could help explain mechanisms underlying multiple forms of psychopathology.

\section{Limitations and Strengths}

Online sampling methods have a few potential limitations. First, unselected recruitment may have limited the generalizability of our results. Participants were predominantly Caucasian and were not selected for clinical symptoms, despite the clinical relevance of our research question. It is promising, though, that participants were diverse in terms of education attainment (more than half reporting they had not finished college), and that rates of clinical symptoms in mTurk samples meet or exceed national levels (Shapiro et al., 2013). Second, it was difficult to retain participants across repeated assessments using mTurk, which could have skewed the characteristics of completers in ways that confounded results. However, retention rates across both waves of data collection (72.61\%, 76.10\%) compare favorably to the $60-80 \%$ range reported in prior studies (Buhrmester et al., 2011; Shapiro et al., 2013). Moreover, we found few differences between retained vs. attritted subjects (retained subjects were older), and when we accounted for possible attrition-related confounds in analyses, there was no effect on significant findings. A third potential problem for studies conducted on mTurk is poor data quality due to inattention or low effort by participants (Paolacci et al., 2010). Nevertheless, the quality of data used in the present study can be considered quite high, due to our stringent inclusion criteria, such as our use of "attention check" items. All participants in the final sample had provided a written description of their upsetting memory, suggesting they had completed the study faithfully.

Ultimately, our hypothesis that low emotional clarity predicts rumination is a causal hypothesis about state-level processes we imagine unfolding in the moments leading to the onset of a rumination episode. But while our hypothesis is causal, it is important to note that our study design does not allow causal inferences about state-level phenomena. We used trait-level, self reported scores of rumination, and we did not manipulate emotional clarity, which would be required in order to conclude that deficits in clarity might actually trigger rumination. Nevertheless, our use of a longitudinal sample can be considered a strength because it allowed us to establish a temporal relationship, with low emotional clarity predicting subsequent change in levels of rumination. The relatively short interval between assessments (approximately 22 days) presents a trade-off. Since we used a trait measure of rumination, scores were fairly stable over time, which reduced our ability to predict changes in them. Perhaps had our data spanned a larger time interval, we would have found larger effects of emotional clarity and stronger moderation by intolerance of uncertainty. On the other hand, the shorter interval makes it likelier that participants were still bothered on a regular basis by the topics they selected for the mood induction at Time 1, and that the changes in rumination we captured had to do with the emotional clarity they experienced when thinking about these topics.

The most notable strengths of our study are related to the mood induction, which reflects our commitment to making discoveries relevant to real human experience, as Susan Nolen-Hoeksema did with her research. Our instructions to participants about what type of memory they should select were deliberately open-ended, leaving participants free to retrieve memories that were important to them in their day-to-day lives. The idiosyncratic nature of participants' 180-character descriptions of their memories, and their reportedly 'unresolved' status, suggests that we succeeded in achieving high external validity with these topics. Participants also reported re-experiencing their memories vividly and becoming upset, which suggests that our mood induction procedure had internal validity as well. Our instructions did not specify which emotions we wished participants to experience, a design element with both pros and cons. Mood inductions have historically targeted a uniform emotional experience among all 
participants (e.g., anger and hostility, Kross et al., 2005). But given that our independent variable was emotional clarity, and our hypothesis framed rumination as a search for answers, we needed to make sure we did not inadvertently tell participants the 'answer' about which emotion they were feeling. Leaving the target emotion unconstrained likely produced a wider range in emotional clarity among participants and ensured a more naturalistic degree of emotional clarity, since in everyday life people do not have psychologists naming emotions associated with particular experiences. A downside, however, is that participants' emotions may have been relatively mixed or complex, and this complexity may have been confounded with emotional clarity ratings. Much more research is needed to help tease apart the relationship between the structure of mixed affective responses and the experience of emotional clarity, which is likely quite complicated (see Boden, Thompson, Dizén, Berenbaum, \& Baker, 2013). A final strength related to our mood induction was that it allowed us to assess emotional clarity at the state level. Because affective experiences are ineffable and difficult to remember accurately, reporting on them as they unfold increases construct validity (Robinson \& Clore, 2002).

\section{Clinical Implications and Future Directions}

Our findings indicate a number of possible avenues for treatment that may help prevent patients from falling into ruminative episodes. An obvious treatment target is emotional clarity itself: patients might benefit from increasing their ability to understand their emotions. Modern psychotherapies have already begun to incorporate training on identifying and labeling emotions with the assumption that these skills help patients better regulate their emotions (Barlow et al., 2010; Linehan, 1993; Mennin \& Fresco, 2014). However, given that the main effect of emotional clarity was only marginal in our sample, perhaps low emotional clarity does not increase risk for rumination on its own. Rather, as our moderation result suggests, the problem may arise only when people are dissatisfied with a low level of clarity. Thus, our study points to a second potential treatment target: intolerance of ambiguity. In order to keep from ruminating, some patients might benefit from learning to tolerate or accept ambiguous emotional states without following the temptation to look for answers by ruminating. An existing treatment targeting intolerance of uncertainty (Dugas et al., 2003; Ladoucer et al., 2000) could serve as a guide. Our results begin to suggest that such techniques could be incorporated profitably into rumination-focused interventions (see Watkins et al., 2011) to help reduce the allure of ruminating.

We consider it essential for future research to address some additional questions about the relationship between emotional clarity and rumination that could inform clinical interventions. First, to what extent might people use rumination to search for emotional clarity on purpose? Participants in meta-cognitive studies consciously perceive benefits of ruminating (e.g., Papageorgiou \& Wells, 2001; 2002), so perhaps some individuals deploy rumination as a strategy for responding to low emotional clarity deliberately. On the other hand, emotion regulation often proceeds unconsciously (Gyurak, Gross, \& Etkin, 2011), and individuals with low emotional clarity may have particularly reduced awareness of their affective processes (Salovey et al., 1995). For interventions to interrupt the link between low emotional clarity and rumination, it may be necessary first to increase some patients' awareness of when and why they ruminate.

Secondly, if people turn to rumination in order to increase their emotional clarity, does it actually work? As we noted in our introduction, Lyubomirsky and Nolen-Hoeksema (1993) found that participants who had been induced to ruminate versus distract themselves later rated themselves as more insightful on a trait measure of insight. But because that study did not assess self-reported insight before participants ruminated, it would be premature to conclude that ruminating increased their subjective sense of understanding the world. Moreover, there is a conceptual difference between believing oneself to be insightful as an individual versus feeling clear about emotions as they unfold, which makes it hard to translate Lyubomirsky and Nolen-Hoeksema's findings into predictions about emotional clarity. More work is needed to determine whether pursuing emotional clarity by ruminating is fruitless, or whether ruminating does in fact produce the answers ruminators seek, a reward that could reinforce rumination over time. 


\section{Conclusion}

In this investigation, we sought to expand upon the growing literature on rumination as a 'search for answers' (e.g., Papageorgiou \& Wells, 2001, 2002; Watkins \& Baracaia, 2001) by testing whether intolerance of ambiguity would moderate the association between low emotional clarity and rumination. In line with predictions, we found that among participants reporting high intolerance of ambiguity, low emotional clarity was associated with greater levels of rumination a few weeks later. This was not the case for participants who reported being able to tolerate ambiguity. In all, we found preliminary support consistent with a novel hypothesis that the desire to increase emotional clarity might lure some people into ruminating. We attempted to emulate Susan Nolen-Hoekesema's person-inspired approach, and we underscore its value for discovering new factors associated with the initiation and maintenance of ruminative cycles.

\section{Acknowledgements}

We are grateful to John Dovidio and Brett Marroquín for their insightful feedback on earlier versions of this article.

Susan Nolen-Hoeksema assisted in developing the theoretical framework for the program of research represented in the present article and funded data collection.

\section{References}

Aldao. A. (2013). The future of emotion regulation research: Capturing context. Perspectives on Psychological Science, 8, 155-172. http://dx.doi.org/10.1177/1745691612459518

Aldao, A., \& Nolen-Hoeksema, S. (2012). The influence of context on the implementation of adaptive emotion regulation strategies. Behaviour Research and Therapy, 50(7-8), 493-501. http://dx.doi.org/10.1016/j.brat.2012.04.004

Aldao, A., Nolen-Hoeksema, S., \& Schweizer, S. (2010). Emotion-regulation strategies across psychopathology: A meta-analytic review. http://dx.doi.org/10.1016/j.cpr.2009.11.004

Barlow, D. H., Farchione, T. J., Fairholme, C. P., Ellard, K. K., Boisseau, C. L., Allen, L. B., \& Ehrenreich, J. T. (2010). Unified protocol for transdiagnostic treatment of emotional disorders: Therapist guide (1 ed.). New York: Oxford University Press.

Barrett, L. F., Gross, J., Christensen, T. C., \& Benvenuto, M. (2001). Knowing what you're feeling and knowing what to do about it: Mapping the relation between emotion differentiation and emotion regulation. Cognition \& Emotion, 15(6), 713-724. http://dx.doi.org/10.1080/02699930143000239

Baumeister, R. F., Vohs, K. D., DeWall, C. N., \& Zhang, L. (2007). How emotion shapes behavior: Feedback, anticipation, and reflection, rather than direct causation. Personality and Social Psychology Review, 11(2), 167203. http://dx.doi.org/10.1177/1088868307301033

Boden, M. T., Bonn-Miller, M. O., Kashdan, T. B., Alvarez, J., \& Gross, J. J. (2012). The interactive effects of emotional clarity and cognitive reappraisal in posttraumatic stress disorder. Journal of Anxiety Disorders, 26(1), 233-8. http://dx.doi.org/10.1016/j.janxdis.2011.11.007

Boden, M. T., Gross, J. J., Babson, K. A., \& Bonn-Miller, M. O. (2013). The interactive effects of emotional clarity and cognitive reappraisal on problematic cannabis use among medical cannabis users. Addictive Behaviors, 38(3), 1663 - 1668. http://dx.doi.org/10.1016/i.addbeh.2012.09.001

Boden, M. T., Thompson, R. J., Dizén, M., Berenbaum, H., \& Baker, J. P. (2013). Are emotional clarity and emotion differentiation related? Cognition \& Emotion, 27(6), 961-78. http://dx.doi.org/10.1080/02699931.2012.751899

Budner, S. (1962). Intolerance of ambiguity as a personality variable. Journal of Personality, (30), 29-50. http://dx.doi.org/10.1111/j.1467-6494.1962.tb02303.x

Buhrmester, M., Kwang, T., \& Gosling, S. D. (2011). Amazon's Mechanical Turk: A new source of inexpensive, yet high-quality, data? Perspectives on Psychological Science, 6(3), 3-5.

http://dx.doi.org/10.1177/1745691610393980

Crump, M. J. C., McDonnell, J. V., \& Gureckis, T. M. (2013). Evaluating Amazon's Mechanical Turk as a tool for experimental behavioral research. PloS One, 8(3), e57410. http://dx.doi.org/10.1371/journal.pone.0057410 
de Jong-Meyer, R., Beck, B., \& Riede, K. (2009). Relationships between rumination, worry, intolerance of uncertainty and metacognitive beliefs. Personality and Individual Differences, 46(4), 547-551.

http://dx.doi.org/10.1016/i.paid.2008.12.010

Dugas, M. J., Ladouceur, R., Léger, E., Freeston, M. H., Langolis, F., Provencher, M. D., \& Boisvert, J. -M. (2003). Group cognitive-behavioral therapy for generalized anxiety disorder: Treatment outcome and long-term followup. Journal of Consulting and Clinical Psychology, 71(4), 821-825. http://dx.doi.org/10.1037/0022006X.71.4.821

Flynn, M., \& Rudolph, K. D. (2010). The contribution of deficits in emotional clarity to stress responses and depression. Journal of Applied Developmental Psychology, 31(4), 291-297. http://dx.doi.org/10.1016/j.appdev.2010.04.004

Freeston, M. H., Rhéaume, J., Letarte, H., Dugas, M. J., \& Ladouceur, R. (1994). Why do people worry? Personality and Individual Differences, 17(6), 791-802. http://dx.doi.org/10.1016/0191-8869(94)90048-5

Giorgio, J. M., Sanflippo, J., Kleiman, E., Reilly, D., Bender, R. E., Wagner, C. A., . . Alloy, L. B. (2010). An experiential avoidance conceptualization of depressive rumination: Three tests of the model. Behaviour Research and Therapy, 48(10), 1021-31. http://dx.doi.org/10.1016/j.brat.2010.07.004

Gohm, C. L., \& Clore, G. L. (2002). Four latent traits of emotional experience and their involvement in well-being, coping, and attributional style. Cognition \& Emotion, 16(4), 495-518. http://dx.doi.org/10.1080/02699930143000374

Goodman, J. K., Cryder, C. E., \& Cheema, A. (2012). Data collection in a flat world: The strengths and weaknesses of Mechanical Turk samples. Journal of Behavioral Decision Making, 26(3), 213-224. http://dx.doi.org/10.1002/bdm.1753

Gotlib, I. H., \& Joormann, J. (2010). Cognition and depression: Current status and future directions. Annual Review of Clinical Psychology, 6, 285-312. http://dx.doi.org/10.1146/annurev.clinpsy.121208.131305

Gratz, K. L., \& Roemer, L. (2004). Multidimensional assessment of emotion regulation and dysregulation: Development, factor structure, and initial validation of the Difficulties in Emotion Regulation Scale. Journal of Psychopathology and Behavioral Assessment, 26(1), 41-54. http://dx.doi.org/10.1023/B:JOBA.0000007455.08539.94

Grenier, S., Barrette, A. -M., \& Ladouceur, R. (2005). Intolerance of uncertainty and intolerance of ambiguity: Similarities and differences. Personality and Individual Differences, 39(3), 593-600. http://dx.doi.org/10.1016/j.paid.2005.02.014

Gyurak, A., Gross, J. J., \& Etkin, A. (2011). Explicit and implicit emotion regulation: A dual-process framework. Cognition \& Emotion, 25(3), 400-12. http://dx.doi.org/10.1080/02699931.2010.544160

Hayes, A. F. (2013). Methodology in the Social Sciences: Introduction to mediation, moderation, and conditional process analysis: A regression-based approach. New York, NY: Guilford Press.

Kashdan, T. B., Ferssizidis, P., Collins, R. L., \& Muraven, M. (2010). Emotion differentiation as resilience against excessive alcohol use: An ecological momentary assessment in underage social drinkers. Psychological Science, 21(9), 1341-7. http://dx.doi.org/10.1177/0956797610379863

Kross, E., Ayduk, O., \& Mischel, W. (2005). When asking "why" does not hurt: Distinguishing rumination from reflective processing of negative emotions. Psychological Science, 16(9), 709-15. http://dx.doi.org/10.1111/j.1467-9280.2005.01600.x

Ladouceur, R., Dugas, M. J., Freeston, M. H., Léger, E., Gagnon, F., \& Thibodeau, N. (2000). Efficacy of a cognitive--behavioral treatment for generalized anxiety disorder: Evaluation in a controlled clinical trial. Journal of Consulting and Clinical Psychology, 68(6), 957-964. http://dx.doi.org/10.1037/0022-006X.68.6.957

Liao, K. Y. -H., \& Wei, M. (2011). Intolerance of uncertainty, depression, and anxiety: The moderating and mediating roles of rumination. Journal of Clinical Psychology, 67(12), 1220-1239. http://dx.doi.org/10.1002/jclp.20846

Linehan, M. (1993). Cognitive-behavioral treatment of borderline personality disorder. New York, NY: The Guilford Press.

Liverant, G. I., Kamholz, B. W., Sloan, D. M., \& Brown, T. A. (2011). Rumination in clinical depression: A type of emotional suppression? Cognitive Therapy and Research, 35(3), 253-265. http://dx.doi.org/10.1007/s10608$\underline{010-9304-4}$ 
Lyubomirsky, S., \& Nolen-Hoeksema, S. (1993). Self-Perpetuating properties of dysphoric rumination. Journal of Personality and Social Psychology, 65(2), 339-349. http://dx.doi.org/10.1037/0022-3514.65.2.339

Martin, L. L., \& Tesser, A. (1996). Some ruminative thoughts. In R. S. Wyer (Ed.), Advances in social cognition (Vol. 9, pp. 1-47). Mahwah, NJ: Lawrence Erlbaum Associates.

McLain, L. (1993). The MSTAT-I: A new measure of an individual's tolerance for ambiguity. Educational and Psychological Measurement, 53(1), 183-189. doi:10.1177/0013164493053001020

McLaughlin, K. A., Mennin, D. S., \& Farach, F. J. (2007). The contributory role of worry in emotion generation and dysregulation in generalized anxiety disorder. Behaviour Research and Therapy, 45(8), 1735-52. http://dx.doi.org/10.1177/0013164493053001020

McLaughlin, K. A., \& Nolen-Hoeksema, S. (2011). Rumination as a transdiagnostic factor in depression and anxiety. Behaviour Research and Therapy, 49(3), 186-93. http://dx.doi.org/10.1016/i.brat.2010.12.006

Mennin, D. S., \& Fresco, D. M. (2009). Emotion regulation as an integrative framework for understanding and treating psychopathology. In A. Kring \& D. M. Sloan (Eds.), Emotion regulation and psychopathology: A transdiagnostic approach to etiology and treatment (pp. 356-79). New York, NY: Guilford Press.

Mennin, D. S., \& Fresco, D. M. (2014). Emotion regulation therapy. 800 In Handbook of emotion regulation (2nd ed., pp. 469-490). Guilford Press: New York

Mennin, D. S., Holaway, R. M., Fresco, D. M., Moore, M. T., \& Heimberg, R. G. (2007). Delineating components of emotion and its dysregulation in anxiety and mood psychopathology. Behavior Therapy, 38(3), 284-302. http://dx.doi.org/10.1016/j.beth.2006.09.001

Moberly, N. J., \& Watkins, E. R. (2010). Negative affect and ruminative self-focus during everyday goal pursuit. Cognition \& Emotion, 24(4), 729-739. http://dx.doi.org/10.1080/02699930802696849

Nolen-Hoeksema, S. (1991). Responses to depression and their effects on the duration of depressive episodes. Journal of Abnormal Psychology, 100(4), 569. http://dx.doi.org/10.1037/0021-843X.100.4.569

Nolen-Hoeksema, S., Wisco, B. E., \& Lyubomirsky, S. (2008). Rethinking rumination. Perspectives on Psychological Science, 3(5), 400-424. http://dx.doi.org/10.1111/j.1745-6924.2008.00088.x

Oppenheimer, D. M., Meyvis, T., \& Davidenko, N. (2009). Instructional manipulation checks: Detecting satisficing to increase statistical power. Journal of Experimental Social Psychology, 45(4), 867-872. http://dx.doi.org/10.1016/j.jesp.2009.03.009

Paolacci, G., Chandler, J., \& Ipeirotis, P. G. (2010). Running experiments on Amazon Mechanical Turk. Judgment and Decision Making, 5(5), 411-419.

Papageorgiou, C., \& Wells, A. (2001). Metacognitive beliefs about rumination in recurrent major depression. Cognitive and Behavioral Practice, 8, 160-164. http://dx.doi.org/10.1016/S1077-7229(01)80021-3

Papageorgiou, C., \& Wells, A. (2002). Positive beliefs about depressive rumination: Development and preliminary validation of a self-report scale. Behavior Therapy, 32(1), 13-26. http://dx.doi.org/10.1016/S00057894(01)80041-1

Pennebaker, W. (1997). Writing about emotional experiences as a therapeutic process. Psychological Science, 8(3), 162-166. http://dx.doi.org/10.1111/j.1467-9280.1997.tb00403.x

Pennycook, G., Cheyne, J. A., Seli, P., Koehler, D. J., \& Fugelsang, J. A. (2011). Analytic cognitive style predicts religious and paranormal belief. Cognition. http://dx.doi.org/10.1037/a0025391

Prince, K. R., Litovsky, A. R., \& Friedman-Wheeler, D. G. (2012). Internet-mediated research: Beware of bots. The Behavior Therapist, 35(5), 85-89.

Pyszczynski, T., \& Greenberg, J. (1987). Self-regulatory perseveration and the depressive self-focusing style: A self-awareness theory of reactive depression. Psychological Bulletin, 102(1), 122.

http://dx.doi.org/10.1037/0033-2909.102.1.122

Robinson, M. D., \& Clore, G. L. (2002). Belief and feeling: Evidence for an accessibility model of emotional selfreport. Psychological Bulletin, 128(6), 934-960. http://dx.doi.org/10.1037//0033-2909.128.6.934

Rose, A. J., Carlson, W., \& Waller, E. M. (2007). Prospective associations of co-rumination with friendship and emotional adjustment: Considering the socioemotional trade-offs of co-rumination. Developmental Psychology, 43(4), 1019-31. http://dx.doi.org/10.1037/0012-1649.43.4.1019

Salguero, J. M., Extremera, N., \& Fernández-Berrocal, P. (2013). A meta-mood model of rumination and depression: Preliminary test in a non-clinical population. Scandinavian Journal of Psychology, 54(2), 166-72. doi:10.1111/sjop.12026 
Salovey, P., Mayer, J. D., Goldman, S. L., Turvey, C., \& Palfai, T. P. (1995). Emotional attention, clarity, and repair: Exploring emotional intelligence using the trait meta-mood scale. In J. W. Pennebaker (Ed.), Emotion, disclosure, and health (pp. 125-154). Washington, DC: American Psychological Association. http://dx.doi.org/10.1111/sjop.12026

Salters-Pedneault, K., Roemer, L., Tull, M. T., Rucker, L., \& Mennin, D. S. (2006). Evidence of broad deficits in emotion regulation associated with chronic worry and generalized anxiety disorder. Cognitive Therapy and Research, 30(4), 469-480. http://dx.doi.org/10.1007/s10608-006-9055-4

Schwarz, N., \& Clore, G. L. (1983). Mood, misattribution, and judgments of well-being: Informative and directive functions of affective states. Journal of Personality and Social Psychology, 45(3), 513-523. http://dx.doi.org/10.1037/0022-3514.45.3.513

Shapiro, D. N., Chandler, J., \& Mueller, P. A. (2013). Using Mechanical Turk to study clinical populations. Clinical Psychological Science, 1(2), 213-220. http://dx.doi.org/10.1177/2167702612469015

Smith, J. M., \& Alloy, L. B. (2009). A roadmap to rumination: A review of the definition, assessment, and conceptualization of this multifaceted construct. Clinical Psychology Review, 29(2), 116-28. http://dx.doi.org/10.1016/i.cpr.2008.10.003

Spokas, M., Luterek, J. A., \& Heimberg, R. G. (2009). Social anxiety and emotional suppression: The mediating role of beliefs. Journal of Behavior Therapy and Experimental Psychiatry, 40(2), 283-91. http://dx.doi.org/10.1016/j.jbtep.2008.12.004

Tabachnik, B. L., \& Fidell, L. S. (2007). Using multivariate statistics. ( $5^{\text {th }}$ ed.). Boston, MA: Pearson Education, Inc. Treynor, W., Gonzalez, R., \& Nolen-Hoeksema, S. (2003). Rumination reconsidered: A psychometric analysis. Cognitive Therapy and Research, 27(3), 247-259. http://dx.doi.org/10.1023/A:1023910315561http://dx.doi.org/10.1521/jscp.2014.33.4.319

Vine, V., \& Aldao, A. (2014). Impaired emotional clarity and psychopathology: A transdiagnostic deficit with symptom-specific pathways through emotion regulation. Journal of Social and Clinical Psychology, 33(4), 319342. http://dx.doi.org/10.1521/iscp.2014.33.4.319

Watkins, E., \& Baracaia, S. (2001). Why do people ruminate in dysphoric moods? Personality and Individual Differences, 30(5), 723-734. http://dx.doi.org/10.1016/S0191-8869(00)00053-2

Watkins, E. R. (2008). Constructive and unconstructive repetitive thought. Psychological Bulletin, 134(2), 163-206. http://dx.doi.org/10.1037/0033-2909.134.2.163

Watkins, E. R., Mullan, E., Wingrove, J., Rimes, K., Steiner, H., Bathurst, N., .. Scott, J. (2011). Ruminationfocused cognitive-behavioural therapy for residual depression: Phase II randomised controlled trial. The British Journal of Psychiatry: The Journal of Mental Science, 199(4), 317-22. http://dx.doi.org/10.1192/bjp.bp.110.090282

Yook, K., Kim, K. -H., Suh, S. Y., \& Lee, K. S. (2010). Intolerance of uncertainty, worry, and rumination in major depressive disorder and generalized anxiety disorder. Journal of Anxiety Disorders, 24(6), 623-8. doi:10.1016/j.janxdis.2010.04.003

http://dx.doi.org/10.1016/j.janxdis.2010.04.003 